\title{
EFFECT OF COLLAGEN I GEL ON APOPTOSIS OF RAT HEPATIC STELLATE CELLS
}

\author{
Lenka Bittnerová ${ }^{1}$,Alena Jiroutová ${ }^{1}$, Emil Rudolf ${ }^{2}$, Martina Řezáčová ${ }^{1}$, Jiří Kanta ${ }^{1}$
}

Charles University in Prague, Faculty of Medicine in Hradec Králové, Czech Republic: Department of Medical Biochemistry ${ }^{1}$ and Department of Medical Biology and Genetics ${ }^{2}$

Summary: Activated hepatic stellate cells (HSC) are a major source of fibrous proteins in cirrhotic liver. Inducing or accelerating their apoptosis is a potential way of liver fibrosis treatment. Extracellular matrix (ECM) surrounding cells in tissue affects their differentiation, migration, proliferation and function. Type I collagen is the main ECM component in fibrotic liver. We have examined how this protein modifies apoptosis of normal rat HSC induced by gliotoxin, cycloheximide and cytochalasin $\mathrm{D}$ in vitro and spontaneous apoptosis of $\mathrm{HSC}$ isolated from $\mathrm{CCl}_{4}$-damaged liver. We have found that type I collagen gel enhances HSC apoptosis regardless of the agent triggering this process.

Key words: Hepatic stellate cells; Collagen I; Apoptosis; Gliotoxin; Cykloheximide; Cytochalasin D

\section{Introduction}

Liver fibrosis represents a significant worldwide health problem. It is a response of liver to repeated injury and it is characterized by breakdown of normal extracellular matrix (ECM) resembling basement membrane in composition and by accumulation of ECM containing fibrillar type I collagen. Although more than one potential source of ECM exist, the largest part of connective tissue components is synthesized by activated hepatic stellate cells (HSC) (7).

HSC are located in the space of Disse between endothelial cells and parenchymal cells and their main function is the uptake and storage of vitamin $\mathrm{A}$ and other retinoids. As a result of liver injury HSC loose cytoplasmic lipid droplets, proliferate and are transformed to myofibroblastic cells with prominent $\alpha$-smooth muscle actin ( $\alpha$-SMA) fibres. Quiescent HSC express type III and type IV collagen, activated HSC produce increasing amounts of type I collagen (15). HSC activation observed in vivo can be reproduced to a large extent by cultivation of these cells on plastic surface $(5,12)$. Excessive deposition of ECM, especially of collagen I, may influence morphology, function and fate of HSC as shown by cultivation of these cells on collagen gel (22).

Activated HSC undergo spontaneous apoptosis both in vitro and in vivo (21). Enhancing this process could lead to a more rapid resolution of liver fibrosis $(2,4)$. The presence of connective tissue septa and parenchymal nodules together with changes in vascularity and blood flow lead to liver dysfunction that is not reversible to any significant degree. However, when the injurious agent, e.g. $\mathrm{CCl}_{4}$ treatment, causing liver fibrosis in rats, is removed at an early stage of fibrosis development, normal liver architecture is restored. Regression of liver fibrosis has also been observed in patients suffering from chronic viral infection or alcoholic or non-alcoholic steatohepatitis following therapy or the removal of the injurious agent $(3,19)$.

Understanding of the control of HSC activation and apoptosis may lead to novel therapeutic approaches for the treatment of hepatic fibrosis (4). A fungal metabolite gliotoxin (GLT) accumulates both in cultured HSC and hepatocytes but HSC are much more sensitive to its action. The target of GLT is adenine nucleotide transporter on the inner mitochondrial membrane (18). Other drugs used to induce apoptosis are cycloheximide (CHX), the protein synthesis inhibitor (16), and cytochalasin D (CYT D) that disrupts actin microfilaments (20).

ECM modulates differentiation, migration, proliferation and activation of HSC. Signalling by ECM components is transmitted by cellular receptors the most important of which are integrins. Molecules of ECM proteins with exposed integrin-binding regions, molecular fragments resulting from protein degradation as well as growth factors and cytokines stored in the ECM influence these cellular activities (23). The effect of ECM on HSC apoptosis has not been studied yet. We have used gel made of type I collagen, the main component of fibrotic liver ECM, to study how it affects spontaneous apoptosis of $\mathrm{HSC}$ isolated from $\mathrm{CCl}_{4}$-damaged liver and the apoptosis of normal HSC exposed to apoptosis inducing agents, gliotoxin, cycloheximide and cytochalasin $\mathrm{D}$, in vitro. Apoptosis was quantified by a specific staining of cell nuclei and by flow cytometry. We have found that type I collagen enhances HSC apoptosis regardless of the agent triggering this process. 


\section{Materials and Methods}

\section{Animal treatment, cell isolation, culture and proliferation assay}

All experiments were approved by the Ethics Committee of the Medical Faculty in Hradec Králové. Male Sprague-Dawley rats (Anlab, Prague, Czech Republic) weighing $350-450 \mathrm{~g}$ were used. They were maintained in an air-conditioned room at $22{ }^{\circ} \mathrm{C}$ and fed commercial pelleted diet ad libitum. Some of them received 3 doses of carbon tetrachloride dissolved in olive oil $(1 \mathrm{ml} / \mathrm{kg}$ of $1: 1 \mathrm{v} / \mathrm{v}$ solution). The time interval between the doses was 4 days. A gastric gavage was used for $\mathrm{CCl}_{4}$ administration. These rats were used 24 hours after the last $\mathrm{CCl}_{4}$ dose.

Rat liver was perfused in situ with $0.2 \%$ pronase (Roche, Prague) and $0.013 \%$ collagenase (Roche) in Hank's balanced salt solution (HBSS). The resulting cell suspension was centrifuged on Optiprep (Axis-Shield, Oslo, Norway) density gradient as described by Jiroutová et al. (12). Cell viability determined by trypan blue staining was greater than $95 \%$. The cells were seeded on polystyrene dishes or on type I collagen gel and were cultured in Dulbecco medium (DMEM, Sigma, Prague) containing 10\% fetal bovine serum, $4 \mathrm{mM}$ glutamine, $100 \mathrm{U} / \mathrm{ml}$ penicillin and $100 \mu \mathrm{g} / \mathrm{ml}$ streptomycin. The percentage of vitamin A-positive cells was about $70 \%$ after isolation. However, vitamin A content in HSC population is variable and vitamin A fluorescence bleaches in UV light. Therefore the positivity for glial fibrilar acidic protein (GFAP), a specific marker of quiescent HSC (17), was tested as described by Jiroutová (11). It was greater than $95 \%$.

The cells were harvested and counted 1, 2, 3, 6 and 7 days after plating. To assess the proliferation of the cells on plastic the cells were trypsinized and the cells growing on collagen were released by treating the gel with collagenase (Serva, Heidelberg, Germany) dissolved in HBSS, final concentration $1 \mathrm{mg} / \mathrm{mL}$. Trypan blue-negative cells were taken into account. The cells isolated from normal liver are termed N-HSC, the cells isolated after 3 doses of $\mathrm{CCl}_{4}$ are termed C3-HSC.

Type I collagen was extracted from rat tail tendons with cold $0.25 \mathrm{M}$ acetic acid. It was dialyzed against $0.02 \mathrm{M}$ acetic acid and filter-sterilized. The concentration was adjusted to $1.33 \mathrm{mg} / \mathrm{mL}$. Three volumes of collagen solution were mixed with 1 volume of $4 \times$ concentrated DMEM to obtain a final concentration of $1 \mathrm{mg}$ collagen $/ \mathrm{mL}$. Gels were formed after an hour incubation in an $\mathrm{CO}_{2}$ incubator (13).

$\mathrm{N}-\mathrm{HSC}$ were used in the experiments with toxins. The cells cultured for 2 days were regarded as quiescent (12). They were cultivated on plastic or on collagen gel for 7 days and thereafter were treated with $1.5 \mu \mathrm{M}$ GLT (Sigma) for 5 hours (18), $75 \mu \mathrm{M}$ CHX (Calbiochem Merck, Prague) for 14 hours (16) or $5 \mu \mathrm{g} / \mathrm{ml}(0.01 \mu \mathrm{M})$ CYT D (Sigma) for 24 hours (17). The toxins were dissolved in DMSO and diluted to a desired concentration in cultiva- tion medium. Final concentration of dimethylsulfoxide (DMSO, Sigma) was $1 \%$. DMSO is considered as nontoxic to HSC at this concentration (26). Only $1 \%$ DMSO was applied to control cells.

\section{Immunocytochemistry}

The cells were fixed in $98 \%$ ethanol for 10 minutes. They were permeabilized on ice by cold solution of $0.1 \%$ Triton X-100 in $0.1 \%$ sodium citrate for $5 \mathrm{~min}$. Nonspecific binding sites were blocked by $10 \%$ fetal bovine serum in phosphate-buffered saline (PBS) for $30 \mathrm{~min}$. The cells were incubated with the primary antibody at $4{ }^{\circ} \mathrm{C}$ overnight. Anti- $\alpha$-smooth muscle actin ( $\alpha$-SMA) clone 1A4 (Sigma) was diluted 1:400. The secondary antibody was Cy3-conjugated AffiniPure Donkey Anti Rabbit IgG (Jackson Immunoresearch Europe, Newmarket, UK); it was diluted $1: 2,000$ and the cells were incubated in the dark for 1 hour. Nuclei were stained with 4',6-diamidino-2-phenylindole (DAPI, Sigma) for 2 min. Unspecific mouse immunoglobulins served as negative controls. Cells were washed with PBS, mounted in polyvinylalcohol mounting (Sigma) and studied under Nikon Eclipse fluorescent microscope.

\section{Detection of apoptosis}

\section{A. Determination of apoptosis using acridine orange and ethidium bromide}

Apoptosis was quantified by fluorescence microscopy after addition of a mixture of acridine orange (AO, Sig$\mathrm{ma}$ ), final concentration $10 \mu \mathrm{g} / \mathrm{ml}$, and ethidium bromide (EtBr, Sigma), $10 \mu \mathrm{g} / \mathrm{ml}$. The cells were stained without fixation or enzymatic treatment and the total number of normal and apoptotic cells was determined. Apoptotic cells were identified by their shrunken, absent or budding cytoplasm, condensed budding and fragmented nuclei and fluorescence enhancement by condensed chromatin. The cells in the final state of apoptosis turned orange-red. The apoptotic index refers to the percentage of apoptotic cells in the examined population. Two hundred and fifty cells were counted in one experiment; the means of 4 experiments are shown.

\section{B. Detection of changes in nuclear morphology by DAPI staining}

HSC were fixed in 4\% paraformaldehyde solution for 10 minutes and washed with PBS for $5 \mathrm{~min}$. at room temperature. DAPI staining solution $(1 \mu \mathrm{g} \mathrm{DAPI} / \mathrm{mL})$ was added, the cells were incubated for $5 \mathrm{~min}$. and examined under a fluorescence microscope. DAPI was used to detect nuclear changes - condensation and margination of chromatin and nuclear fragmentation. The unchanged nuclei were elliptical, blue and diffusely stained. On the contrary, 
the typical apoptotic nuclei were shrunken, crimped and contained condensed chromatin. The apoptotic index was calculated.

\section{Analysis of DNA content by flow cytometry}

Changes in the DNA content in the cells reflecting various phases of the cell cycle and apoptosis were analyzed by flow cytometry. Floating cells were collected at indicated time intervals. Cells adhering to plastic were harvested by trypsinization and added to floating cell fraction. Collagen gels were hydrolysed by collagenase, final concentration $1 \mathrm{mg} / \mathrm{mL}$. The cells were centrifuged and washed with PBS. The cell pellets were resuspended in ice-cold $70 \%$ ethanol to permeabilize the cellular membrane and then incubated at room temperature in phosphate/citrate buffer $\left(192 \mathrm{ml} 0.2 \mathrm{M} \mathrm{Na}_{2} \mathrm{HPO}_{4}+8 \mathrm{ml} 0.1 \mathrm{M}\right.$ citric acid, $\mathrm{pH}$ 7.8) for $5 \mathrm{~min}$. The cells were stained with propidium iodide (PI, Sigma), final concentration $50 \mu \mathrm{g} / \mathrm{mL}$, in Vindelov's solution at $37^{\circ} \mathrm{C}$ for 60 minutes. DNA content was determined by flow cytometer Cytomics FC500 (Beckman Coulter) using $15 \mathrm{~mW}$ argon-ion laser with excitation capabilities at $488 \mathrm{~nm}$, and the total emission above $560 \mathrm{~nm}$ was recorded. List mode data were analyzed using Multicycle AV software (Phoenix Flow Systems, Inc.) and CXP (Beckman Coulter). The cells with lower amount of DNA than the cells in G1 phase (i.e. the subG1 peak) were considered apoptotic.

\section{Statistical analysis}

All assays were performed in quadruplicates. The results are presented as means \pm S.E.M. Significance of the differences between means was assessed using two-tailed Student's t tests. Values of $\mathrm{p} \leq 0.05$ were considered significant.

\section{Results}

\section{Activation and proliferation of HSC on plastic and on collagen gel}

HSC isolated from normal rat liver (N-HSC) were cultured on plastic or on collagen I gel for 6 days. They were rounded on plastic on day 2 which corresponds to their quiescent state. They became activated within the next 4 days and on day 6 they were well-spread, flattened with extensive stress fibres positive for $\alpha$-SMA (Fig. 1A left).

In contrast, most cells plated on collagen gel were spread as early as on day 2 . Their bodies were slimmer compared to the cells on plastic and they showed fine cellular processes. Well-developed fine branched processes were elongated and resembled the star-shape stellate cells found in vivo. Some cells retained their circular shape (Fig. 1A right).
HSC isolated from injured liver 24 hours after the third dose of $\mathrm{CCl}_{4}(\mathrm{C} 3-\mathrm{HSC})$ and plated on plastic showed two different patterns: one was apoptotic (the cells were rounded with pyknotic nuclei and apoptotic bodies) while the other cells became flat and polygonal with developed processes after 6 days (Fig. 1B left). C3-HSC spread well on collagen 2 days after isolation and differed greatly from the cells on plastic but the differences disappeared by day 6 (Fig. 1B right).

The adherence of N-HSC to the plastic surface was lower than the adherence to collagen but the number of these cells began to increase after a 2 day lag and it was equal to that on collagen on day 6. C3-HSC numbers on collagen gel did not increase, on day 6 and 7 they were significantly lower compared to plastic (Fig. 1C).

$\alpha$-SMA is a typical cellular marker of activated HSC. Its expression was low in N-HSC after 2 days of cultivation on plastic when $14 \%$ of cells were positive but it increased rapidly and $98 \%$ cells were positive by day 6 . Seeding on collagen lead to earlier HSC activation but only $76 \%$ cells were positive by day 6 . In vivo activated $\mathrm{C} 3$-HSC were $\alpha$-SMA positive as early as 2 days after isolation but the expression of the marker in the cells on collagen decreased to $63 \%$ by day 6 (Fig. 1D).

\section{Apoptosis of HSC activated in vivo}

$\mathrm{AO} / \mathrm{EtBr}$ and DAPI staining was used to determine the percentage of cells within the population of $\mathrm{C} 3-\mathrm{HSC}$ that undergo apoptosis after isolation (day 0 ) and on days 1, 2, 3 and 6 (Fig. 2B). Twenty-seven percent of C3-HSC showed apoptotic features after isolation. Collagen gel significantly promoted apoptosis that reached the maximal level on the second day after isolation (40\%) and decreased to $23 \%$ on day 6 . An inverse effect was seen in the cells cultured on plastic dishes, $22 \%$ of apoptotic cells were observed on the first day of cultivation and a peak (34\%) was reached on day 6. Fluorescence photomicrographs C3-HSC stained by $\mathrm{AO} / \mathrm{EtBr}$ on plastic and on collagen gel on day 2 are shown in Fig. 2C. Live cells with normal green nucleus predominated on plastic, late apoptotic or necrotic red cells were visible on collagen gel. DAPI staining in the same experiment is shown in Fig. 2D. Cells in collagen gel had higher frequency of condensed chromatin.

Flow cytometry detects apoptotic cells with degraded DNA as cells with hypodiploid DNA content that are represented in so-called "sub-G1" peaks on DNA histograms. The results obtained using flow cytometry resembled those obtained by staining the cells but the differences between the cells cultured on plastic and on collagen were much more pronounced on day 2. Apoptosis of C3-HSC promoted by collagen gel reached maximum on the second day of cultivation (41\%) and decreased to $11 \%$ on day 6 . Apoptosis of cells cultivated on plastic increased from $8 \%$ detected on the second day to $33 \%$ on day 6 (Fig. 2A). 
A

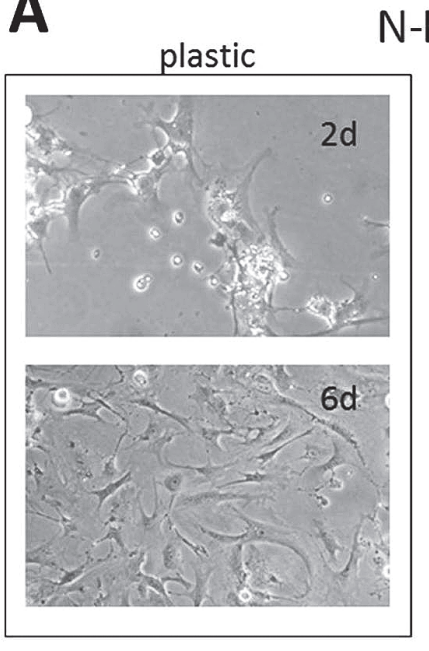

C
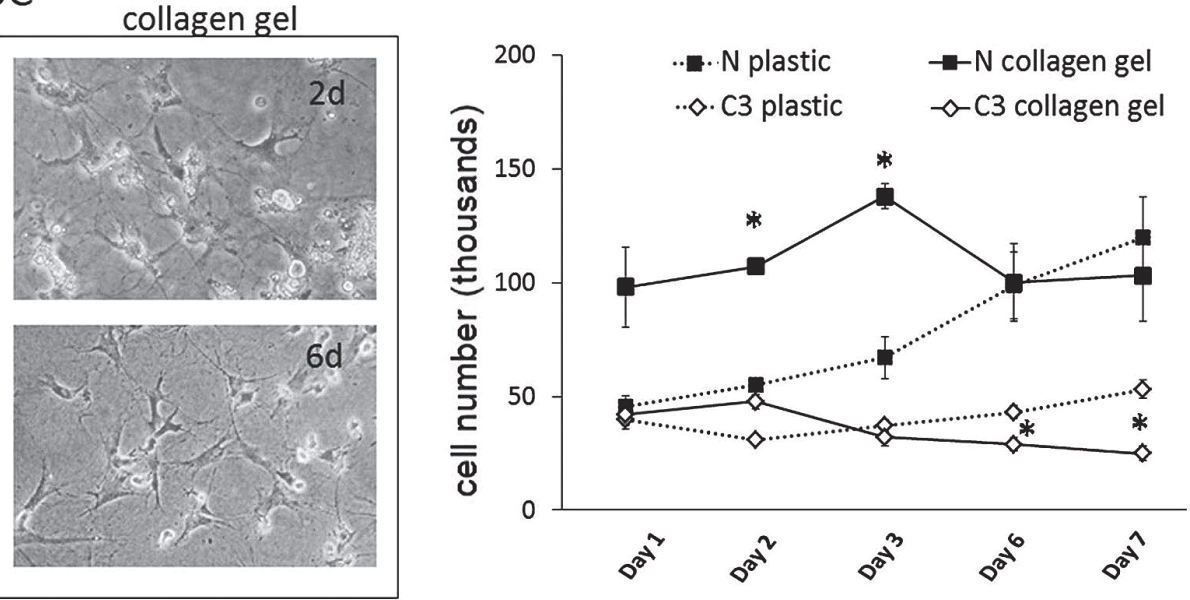

D

Percentage of $\alpha$-SMA positive cells

$\mathrm{N}-\mathrm{HSC}$ Day 2 Day 6

plastic $\quad 14 \pm 2 \quad 98 \pm 2$

collagen gel $40 \pm 3^{*} 76 \pm 5^{*}$

C3-HSC

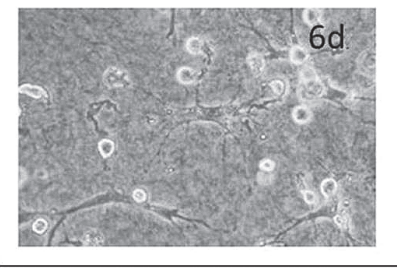

plastic

collagen gel $\quad 98 \pm 1$
$95 \pm 2$

$63 \pm 5^{*}$

Fig. 1: A) Morphology of N-HSC and B) C3-HSC. The cells were cultivated on plastic dishes or on collagen I gel for 2 and 6 days, respectively. Phase contrast, original magnification $200 \times(\mathrm{A}$ and B, day 2) or $100 \times(\mathrm{B}$, day 6). An apoptotic cell is shown in the inset. C) N-HSC $\left(5 \times 10^{5}\right)$ and C-HSC $\left(5 \times 10^{5}\right)$ were seeded on plastic dishes or on collagen gel and cell numbers were determined after trypsinization or after collagen digestion by collagenase. Means \pm S.E.M. $(n=4)$. * Significant difference ( $\mathrm{p} \leq$ 0.05), plastic vs. collagen gel. N-N-HSC, C3 - C3-HSC. D) Immunofluorescence was used for $\alpha$-SMA detection. Positive cells were counted. Means \pm S.E.M. $(n=4)$. ${ }^{*}$ Significant difference $(p \leq 0.05)$, plastic vs. collagen gel.

\section{Apoptosis of HSC treated in vitro by apoptosis-inducing agents}

HSC isolated from normal rat liver were cultured on plastic or on collagen I gel for 7 days and then the three toxins known to induce apoptosis were added. GLT was used at $1.5 \mu \mathrm{M}$ for 5 hours, $\mathrm{CHX}$ at $75 \mu \mathrm{M}$ for 15 hours and CYT D at $5 \mu \mathrm{g} / \mathrm{ml}$ for 24 hours as described before (16, $18,20)$. Control group of N-HSC was treated with DMSO. Apoptosis was evaluated both by fluorescence staining and by flow cytometry.

Fig. 3 shows that all three toxins reduced the number of N-HSC cultivated on plastic or on collagen gel via apoptosis. They caused prominent morphological changes in
$\mathrm{N}-\mathrm{HSC}$ - a decrease in the number of cytoplasmic processes, cell rounding, fragmentation of the nucleus and condensation of nuclear chromatin (Fig. 3A). The percentage of apoptotic cells on plastic after toxin treatment was lower ( 15 to $20 \%$ ) when determined by staining than when flow cytometry was used ( 31 to $36 \%$ ). Collagen gel potentiated apoptosis in all cases. The results were statistically significant (Fig. 3B, C).

\section{Discussion}

The components of ECM greatly influence cell morphology, proliferation and function. Type I collagen provides a substantial part of ECM in cirrhotic liver. Micro- 
A

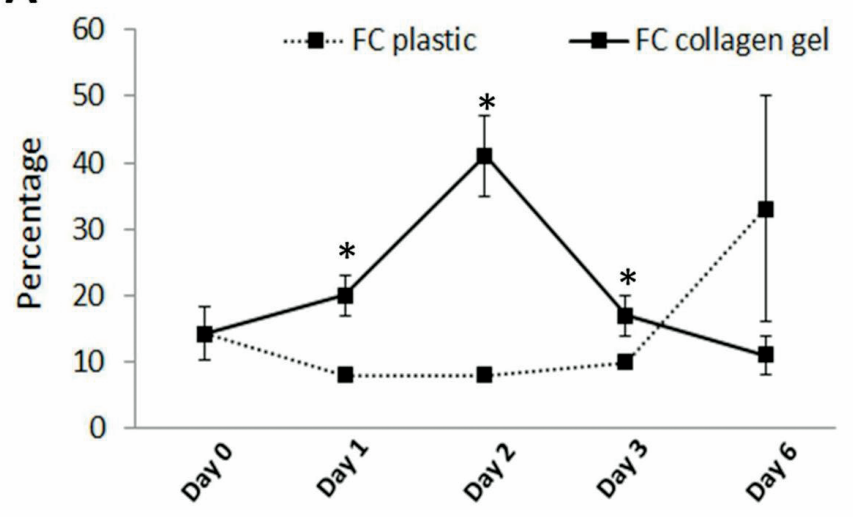

B

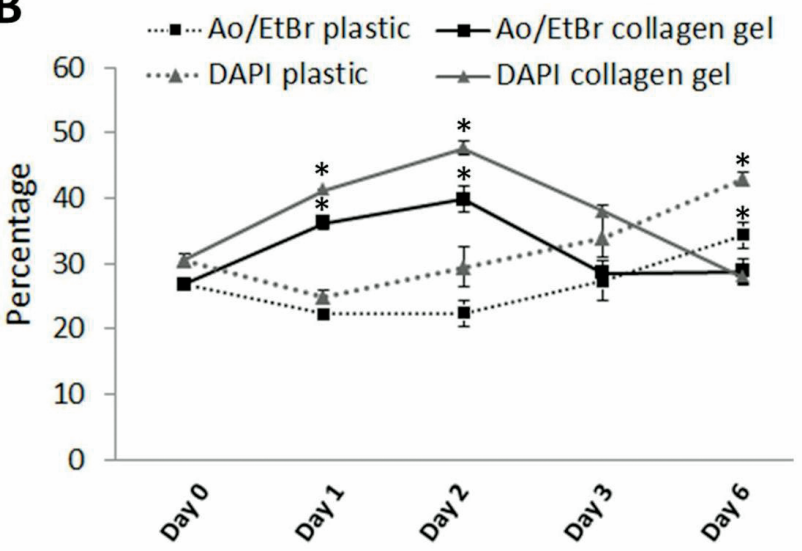

D

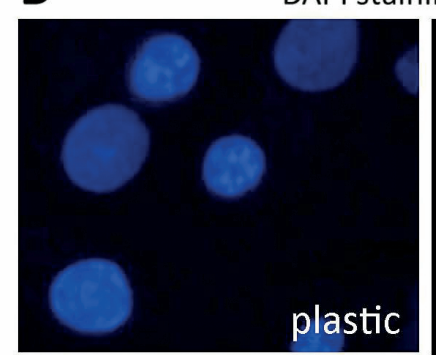

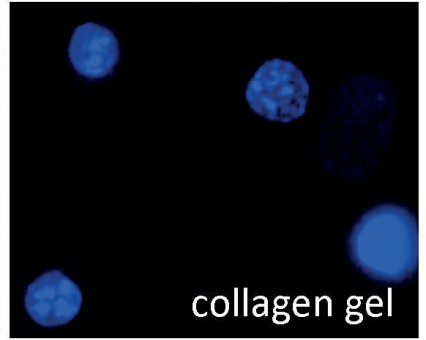

Fig. 2: A) Percentage of apoptotic of C3-HSC determined by flow cytometry (FC) analysis of DNA content and B) by staining with acridine orange/ethidium bromide $(\mathrm{AO} / \mathrm{EtBr})$ or DAPI. Means \pm S.E.M. $(\mathrm{n}=4)$. * Significant difference $(\mathrm{p} \leq 0.05)$, plastic vs. collagen gel. C) Fluorescence photomicrographs of C3-HSC stained by AO/EtBr. Cells were cultivated on plastic and on collagen gel for 2 days. AO permeates all cells and makes the nuclei appear green, while EtBr is only taken up by cells when plasma membrane integrity is lost, and stains the nucleus red. Live cells with normal green nucleus predominate on plastic, late apoptotic or necrotic red cells are visible on collagen gel. Magnification 100×. D) DAPI staining of C3-HSC cultivated on plastic and on collagen gel for 2 days. Picture shows typical apoptotic features - cell shrinkage and chromatin condensation in higher percentage on collagen gel. Magnification 400×.

gram quantities of collagen covering culture dishes or 3 -dimensional (3D) collagen gel that more closely resembles tissue are used in the studies of rat liver HSC (24).

The steady state level of collagen $\alpha 1(\mathrm{I}) \mathrm{mRNA}$ is increased $60-70$ fold in HSC activated by plating on plastic surface and the half-life of this mRNA increases from 1.5 hour to 24 hours. HSC thus seem to modify their microenvironment (14). When collagen is provided, HSC spread on it. We observed that both N-HSC isolated from normal liver and $\mathrm{C} 3$-HSC isolated from $\mathrm{CCl}_{4}$-damaged liver spread more quickly on collagen I gel than on plastic. HSC plated on collagen gel showed slender bodies and long extensions. N-HSC plated on plastic proliferated and their number increased twofold between day 1 and day 7 as expected since this is the basic method of HSC activation and multiplication introduced by Friedman (5). We found that N-HSC numbers on the gel did not increase. This result correlates with the findings of Senoo et al. (25) who demonstrated that the proliferation of HSC plated on collagen or into it is retarded when compared with the cells plated on polystyrene.
Apoptosis of HSC is usually studied in normal cells under standard culture conditions and primary HSC isolated from cirrhotic liver are rarely used (6). The apoptosis of $\mathrm{HSC}$ isolated from $\mathrm{CCl}_{4}$-damaged liver and cultured on collagen gel has not been studied yet. In our experiments the number of $\mathrm{C} 3$-HSC activated in vivo did not change during 7 days of activation either on plastic or on collagen gel. Proliferation was not supported under these conditions or it was balanced by apoptosis.

The latter possibility is more likely although the increase in apoptosis was only temporary. The observed percentage of apoptotic C3-HSC was much higher when the cells were plated on collagen gel than on plastic. The determination of apoptosis by cell staining and by flow cytometry yielded similar results. The mechanism of collagen action is not known. Moreover, the number of cells on collagen that stained for $\alpha$-SMA decreased. Collagen partially suppressed the myofibroblastic character of HSC and tended to decrease their numbers. Thus collagen accumulating in fibrotic liver may provide a negative feedback by suppressing accumulation of activated HSC. 

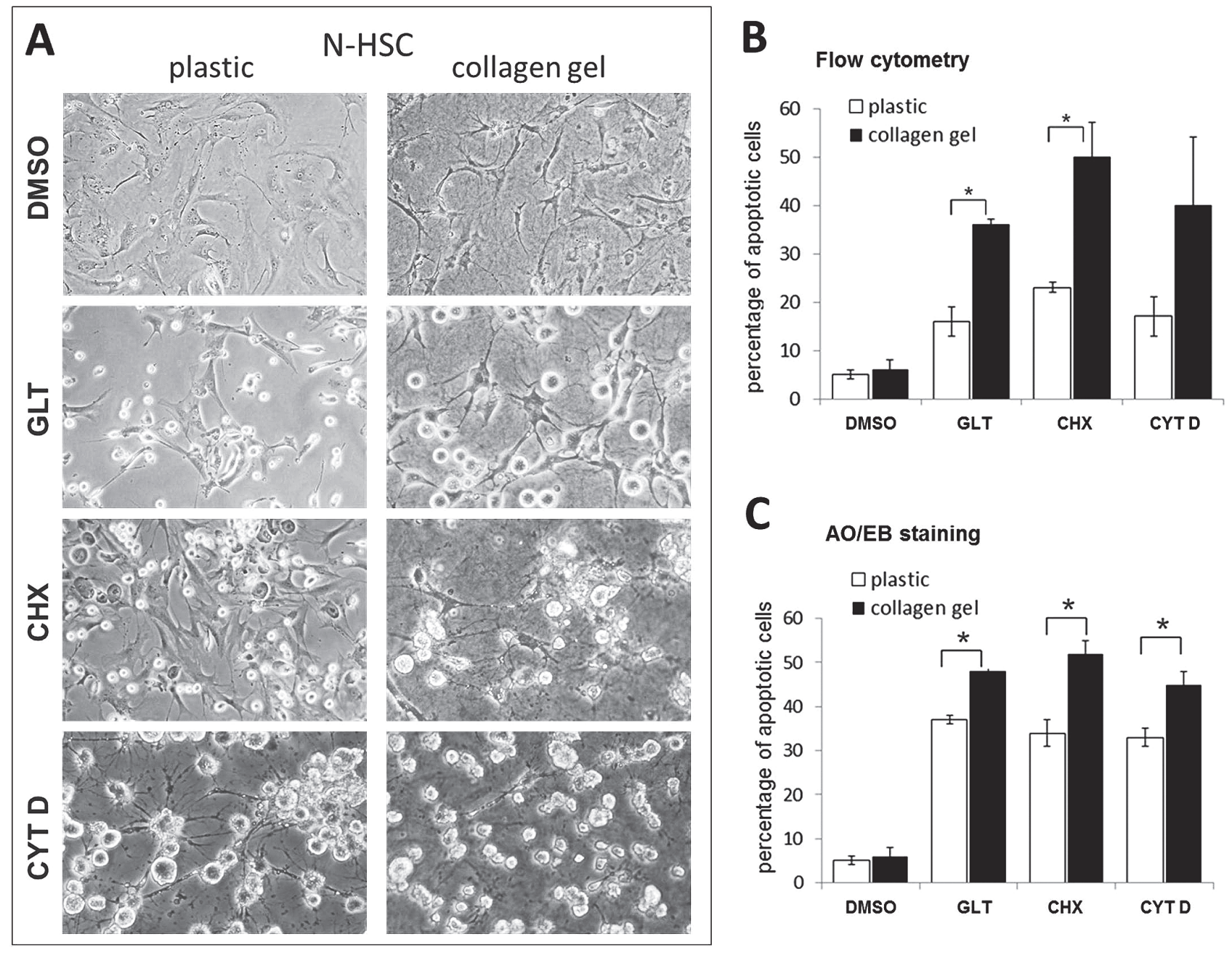

Fig. 3: A) Morphology of N-HSC cultivated with DMSO, gliotoxin (GLT) (1.5 $\mu$ M for 5 hours), cycloheximide (CHX) (75 $\mu \mathrm{M}$ for 14 hours) and cytochalasin D (CYT D) $(5 \mu \mathrm{g} / \mathrm{ml}$ for 24 hours) on plastic or on collagen gel. Original magnification $200 \times$, except GLT $(100 \times)$. B) Percentage of apoptotic N-HSC cultivated on plastic or on collagen gel determined by flow cytometry. C) Percentage of apoptotic N-HSC determined by staining with acridine orange/ethidium bromide (AO/ EtBr). Means \pm S.E.M. $(n=4)$. * Significant difference $(\mathrm{p} \leq 0.05)$, plastic vs. collagen gel.

In vivo studies show that there is a close temporal correlation between HSC apoptosis and matrix degradation suggesting that these events may be linked (3). The density of ECM may play a role. Total viable cell number is much lower when dermal fibroblasts are cultured within low density $(0.66 \%)$ collagen gel than in high density (3-5\%) gel (9). Cell adhesion to collagen fibres is mediated by integrins (10). Integrins $\alpha_{\mathrm{v}} \beta_{3}$ were shown to be involved in the regulation of HSC proliferation and apoptosis (27).

HSC are the main source of connective tissue components in fibrotic liver and enhancing apoptosis of HSC is a potential way of treating this disease (4). However, the action of apoptosis-inducing agents may be unspecific. Hepatocytes are only mildly affected by GLT according to Orr et al. (18) but Anselmi et al. (1) warn that hepatocytes in fibrotic liver are more sensitive to GLT than hepatocytes in normal liver. Kupffer cells and liver endothelial cells are destroyed by the drug (8). The extent of apoptosis in fibrotic liver slices treated in vitro with GLT is much greater than in slices cut from normal liver (8). Our results suggest that collagen I may be an ECM component potentiating the action of GLT and other toxins.

Type I collagen, the main component of liver fibrotic septa, influences multiplication of HSC isolated from normal or $\mathrm{CCl}_{4}$-damaged liver as well as their resistance to apoptosis-causing agents. It potentiates apoptosis regardless of the nature of the initial impulse that triggered programmed cell death.

\section{Acknowledgements}

This work was supported by the programme PRVOUK P37/01. 


\section{References}

1. Anselmi K, Stolz DB, Nalesnik M, et al. Gliotoxin causes apoptosis and necrosis of rat Kupffer cells in vitro and in vivo in the absence of oxidative stress: exacerbation by caspase and serine protease inhibition. J Hepatol 2007; 47: 103-113.

2. Cheng K, Mahato RI. Gene modulation for treating liver fibrosis. Crit Rev Ther Drug Carr Syst 2007; 24: 93-146.

3. Fallowfield JA, Iredale JP. Reversal of liver fibrosis and cirrhosis - an emerging reality. Scott Med J 2004; 49: 3-6.

4. Fallowfield JA, Iredale JP. Targeted treatment for cirrhosis. Expert Opin Ther Targets 2004; 8: 423-435.

5. Friedman SL, Roll FJ, Boyles J, Arenson DM, Bissell DM. Maintenance of differentiated phenotype of cultured rat hepatic lipocytes by basement membrane matrix. J Biol Chem 1989; 264: 10756-10762.

6. Friedman SL. Hepatic stellate cells: protean, multifunctional, and enigmatic cells of the liver. Physiol Rev 2008; 125-172.

7. Guo J, Friedman SL. Hepatic fibrogenesis. Semin Liver Dis 2007; 27: 413-426.

8. Hagens WI, Olinga P, Meijer DKF, et al. Gliotoxin non-selectively induces apoptosis in fibrotic and normal livers. Liver Int 2006; 232-239.

9. Helary C, Zarka M, Giraud-Guille MM. Fibroblasts within concentrated collagen hydrogels favour chronic skin wound healing. J Tiss Engn Regen Med 2012; 6 : 225-237.

10. Imai K, Sato T, Senoo H. Adhesion between cells and extracellular matrix with special reference to hepatic stellate cell adhesion to three-dimensional collagen fibers. Cell Struct Function 2000; 25: 329-336.

11. Jiroutová A, Majdiaková L, Čermáková M, Köhlerová, Kanta J. Expression of cytoskeletal proteins in hepatic stellate cells isolated from normal and cirrhotic rat liver. Acta Med (Hradec Králové) 2005; 48: 137-144.

12. Jiroutova A, Slavkovsky R, Cermakova M, et al. Expression of mRNAs related to connective tissue metabolism in rat hepatic stellate cells and myofibroblasts. Exp Toxicol Pathol 2007; 58: 263-273.

13. Jiroutová A, Peterová E, Bittnerová L, et al. Collagenolytic potential of rat live myofibroblasts. Physiol Res 2013; 62: 15-25.

14. Lang A, Brenner DA. Gene regulation in hepatic stellate cells. Ital J Gastroenterol Hepatol 1999; 31(2): 173-179.
15. Mathew J, Geerts A, Burt AD. Pathobiology of hepatic stellate cells. Hepato-Gastroenterol 1996; 43: 72-91.

16. Murphy FR, Issa R, Zhou X, et al. Inhibition of apoptosis of activated hepatic stellate cells is mediated via effects on matrix metalloproteinase inhibition. J Bio Chem 2002; 277: 11069-11076.

17. Neubauer K, Knittel T, Aurisch S, Fellmer P, Ramadori G. Glial fibrillary acidic protein - a cell type specific marker for Ito cells in vivo and in vitro. J Hepatol 1996; 245: 719-730.

18. Orr JG, Leel V, Cameron GA, et al. Mechanism of action of the antifibrogenic compound gliotoxin in rat liver cells. Hepatology 2004; 40: 232-242.

19. Povero D, Busletta C, Novo E, et al. Liver fibrosis: a dynamic and potentially reversible process. Histol Histopathol 2010; 25: 1075-1091.

20. Preaux AM, D'Ortho MP, Bralet MP, Laperche Y, Mavier P. Apoptosis of human hepatic myofibroblasts promotes activation of matrix metalloproteinase-2. Hepatology 2002; 36: 615-622.

21. Saile B, Matthes N, El Armouiche H, Neubauer K, Ramadori G. The bcl, NFкB and $\mathrm{p} 53 / 21^{\mathrm{WAF} 1}$ systems are involved in spontaneous apoptosis and in the anti-apoptotic effect of TGF- $\beta$ or TNF- $\alpha$ on activated chepatic stellate cells. Eur J Cell Biol 2001; 80: 554-561.

22. Sato M, Suzuki S, Senoo H. Hepatic stellate cells: unique characteristics in cell biology and phenotype. Cell Struct Funct 2003; 28: 105-112.

23. Schuppan D, Ruehl M, Somasundaram R, Hahn EG. Matrix as a regulator of hepatic fibrogenesis. Semin Liver Dis 2001; 21:351-372.

24. Senoo H. Structure and function of hepatic stellate cells. Med Electron Microsc 2004; 37: 3-15.

25. Senoo H, Imai K, Sato M, et al. Three-dimensional structure of extracellular matrix reversibly regulates morphology, proliferation and collagen metabolism of perisinusoidal stellate cells (vitamin A-storing cells). Cell Biol Int 1996; 20: $501-512$.

26. Zeng X, Zhao C, Wang H, et al. Dimethyl sulfoxide decrease type-I and -III collagen synthesis in human hepatic stellate cells and human foreskin fibroblasts. Adv Sci Lett 2010; 3: 496-499.

27. Zhou X, Murphy FR, Gehdu N, et al. Engagement of $\alpha_{\mathrm{v}} \beta_{3}$ integrin regulates proliferation and apoptosis of hepatic stellate cells. J Biol Chem 2004; 279: 23996-24006.

Received: $27 / 02 / 2013$

Accepted in revised form: 31/05/2013

Corresponding author:

Dr. Jiří Kanta, Charles University in Prague, Faculty of Medicine in Hradec Králové, Department of Medical Biochemistry, Šimkova 870, 50038 Hradec Králové, Czech Republic; e-mail: kanta@1fhk.cuni.cz 